\title{
Calculation of Leakage Water and Forecast Actual Water Delivery in Town Drinking Water Supply Systems
}

\author{
Venkata Sanyasi Rao Sasipalli \\ Center for Excellence \\ Computer Technology \\ Hiroshima City, Japan
}

\author{
Zulfadhli Bin Zainuddin \\ RAMTEJ Technologies Corp. \\ Hiroshima City, Japan
}

\author{
Krishnam Raju Gottumukkala \\ Center for Excellence in \\ Computer Technology \\ Visakhapatnam City, India
}

\begin{abstract}
Almost all proposals present forecast data of the variables in focus and conclude the results. However, some variables such as water can change its volume during the traverse from source to end. Such of these variables need to be studied with loss parameters also. This loss parameter here is leakage water. Water demand forecast can be calculated for the coming years, but leakage water also need to be calculated and then actually delivered water to the end users has to be forecast. This paper proposed a model of piping pattern, leakage locations. Calculated leakage water and forecast the actual delivery of water to end users. On the application side, the results of this paper help administrators take decisions on improving infrastructure of water distributions system and take precautions to care the maintenance of the infrastructure. The ideas and methods presented in this paper can be applied to other projects of similar nature. On the academic research side, this formulation helps further in-depth analysis to be carried out to calculate exact leakage water volumes. Water works departments can also benefit from this research.
\end{abstract}

Keywords: Water Demand, Leakage Water, Forecast, Extrapolation, Least Squares

\section{INTRODUCTION}

Problem addressed in this research paper is to calculate water wastage due to leakages and forecast how much water is actually delivered to end users.

As water demand increases, water supply management requires changes. For the last few decades water requirement has been increasing both due to an increase in water usage and reduced water supply. Water leakage reduction in public water systems is a crucial part of water demand management. Especially water supply systems managed by Municipalities, Corporation and other Government organizations pose more threats due to poor management.

Usually, leakage is the largest component of distribution loss yet it is not subject to focus other than management decision by utilities. Leakage in public water supply systems results in loss of purified drinking water but also means of wasting the money and material resources used in abstraction, transportation and treatment. It results in secondary economic loss also, in the form of, damage to the pipe network. Public health concerns as it increases the risk of bacterial contamination of drinking water resources in the cities for human consumption, and can increase pollution loads into the environment.

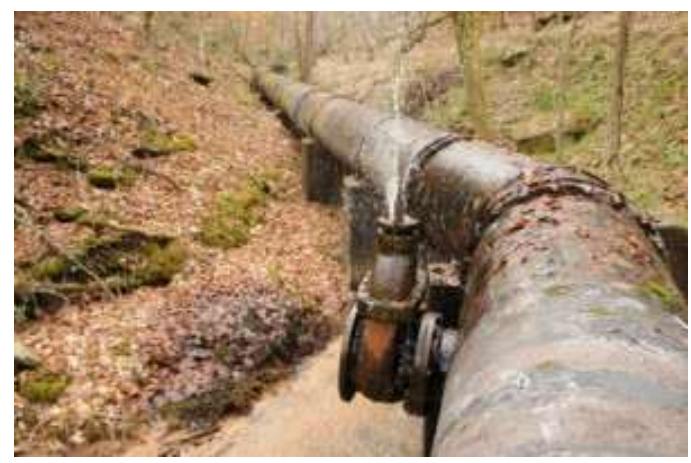

Figure 1: A Trivial Water leakage Location
Most countries have recognized the need to replace the present Water Infrastructure and their Challenges. Million kilometers of pipes beneath the streets need to be replaced because as pipes age, the problems of in-filtration and exfiltration due to leaks increase in sewer pipes and can lead to potential problems such as the collapse of a pipeline or damages to nearby assets [1].

City / town population is continuously increasing every year, it has an impact on the increased clean water consumption. Therefore, the actual data of water volumes is required for the demand fulfillment of how much the water is needed. Data analysis tool is highly needed in the measurement, control processes, formulate information from the available data, and help make decisions based on the available data and predictions [2].

On primary estimates of requirements of lactating women who engage in moderate physical activity in above-average temperatures, a minimum of 7.5 liters per capita per day will meet the requirements of most people under most conditions. This water needs to be of a quality that represents a tolerable level of risk. However, in an emergency situation, a minimum of 15 liters is required. A higher quantity of about 20 liters per capita per day should be assured to take care of basic hygiene needs and basic food hygiene. Laundry / bathing might require higher amounts unless carried out at source.

Local government drinking systems, which manages the distribution of water in towns / cities and their catchment areas. Distribution of clean water from a number of sources is not fully established in some developing countries. This is due to the limited volume of water availability and the lack distribution system management or financial difficulties. The water distribution department must be able to distribute sufficient quantity of quality water in to all users to meet their needs [3].

Most government departments are not implementing the 
forecast tools for determining the quantity of water to distribute. Therefore, the effectiveness and efficiency of water distribution is very low, moreover, it has been causing water distribution leakage that can affect the availability of the water to the end users. This condition would be harmful to the Municipalities as they can not fulfill the users' needs. The unsatisfied users with the service provided can cause a bad image on the Municipalities and their functioning.

The supply source, distribution, wastage water, etc require a properly designed strategy with the placement of the shape of the desired input and output. In this paper we introduce essential pipeline patterns to identify and calculate the water leakages and then forecast actually delivered water amounts, in general and for particular cases.

First of all, what is the relationship among Planning Level, Water Utility Decision Problems and Forecast Attributes for short, medium and long horizons? They are categorized [4] in the below table.

Table 1: Planning Levels and Forecast Horizons

\begin{tabular}{|l|l|l|l|}
\hline $\begin{array}{l}\text { Planning } \\
\text { Level }\end{array}$ & $\begin{array}{l}\text { Decision } \\
\text { Problem }\end{array}$ & $\begin{array}{l}\text { Forecast } \\
\text { Horizon }\end{array}$ & $\begin{array}{l}\text { Forecast } \\
\text { Periodicity }\end{array}$ \\
\hline Operational & $\begin{array}{l}\text { System operation } \\
\text { management and } \\
\text { optimization }\end{array}$ & $\begin{array}{l}\text { Short- } \\
\text { term (less } \\
\text { than 1 } \\
\text { year) }\end{array}$ & $\begin{array}{l}\text { Hourly, } \\
\text { Daily, } \\
\text { Weekly, } \\
\text { Monthly }\end{array}$ \\
\hline Tactical & $\begin{array}{l}\text { Revenue forecast, } \\
\text { Investment } \\
\text { planning, Staging } \\
\text { system } \\
\text { improvement }\end{array}$ & $\begin{array}{l}\text { Medium } \\
\text { term (1- } \\
10 \text { years) }\end{array}$ & $\begin{array}{l}\text { Monthly, } \\
\text { Annual }\end{array}$ \\
\hline Strategic & $\begin{array}{l}\text { Capacity } \\
\text { expansion }\end{array}$ & $\begin{array}{l}\text { Long } \\
\text { term } \\
\text { (more } \\
\text { than 10 } \\
\text { years) }\end{array}$ & \\
& & \multicolumn{2}{|c|}{} \\
\hline
\end{tabular}

Long term planning / strategies can rely on Regression Least Squares [5] to predict the future state through available data in the past and forecast the events in the future on the basis of patterns. The system developed can be added as an extra added system or anew. By combining the expertise of information technology, especially in the field of system forecasting, it is expected to solve the existing problems. Furthermore, decision support systems [6] in water distribution aims to help decision makers utilize particular data and models to solve various problems which are not structured.

\section{WATER LEAKAGE PATTERNS}

The water leakage is as severe as the demand of water; we need to identify potential leakage locations. The potential leakage locations are identified in the below Figure 2.

This is generalized pattern and leaks or holes in the pipes are not considered in the Figure, leaks at junctions are stage 1 leakage potentials.

\subsection{Leakage Points}

In view of water distribution need, we needed information

WS: Water Source

LP: Leak Point

TJ: Over Head Tank Junction
OHT: Over Head Tank

AJ: Area Junction, covered by a certain OHT

STR: Street

IH: Individual House

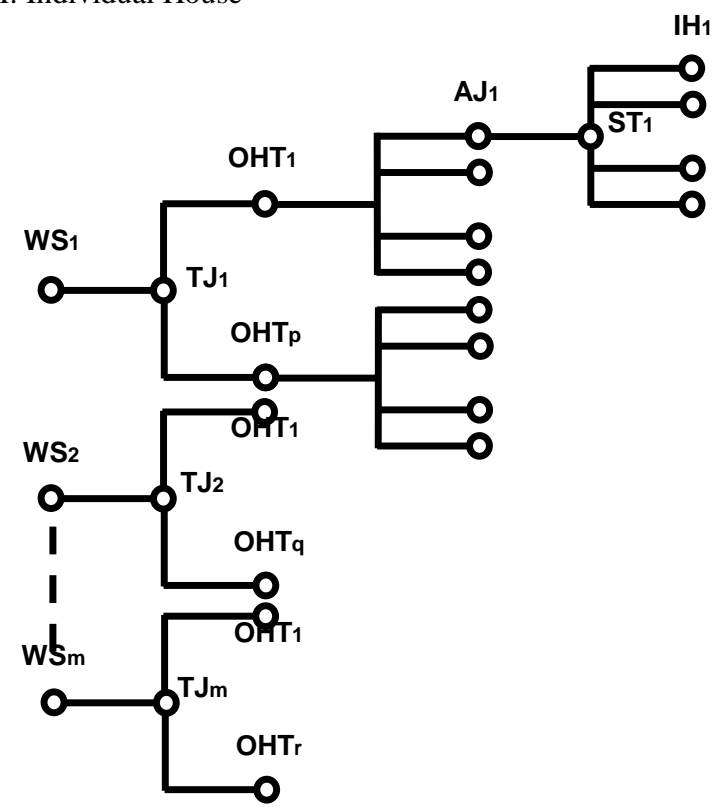

Figure 2: Piping Patterns and Leakage Segments

Segment 1: Pipes between WS and TJ

Segment 2: Pipes between TJ and OHT

Segment 3: Pipes between OHT and AJ

Segment 4: Pipes between AJ and STR

Segment 5: Pipes between STR and IH

\subsection{Math Formulation}

From the section 2.1, we can formulate a generalized model for leakage of water.

Total amount of leakage water in the amount of water supplied from Source 1 can be calculated as below.

The number of potential leakage segments can be identified as minimum 5 as shown in Section 2.1. Then we can formulate the total leakage water (TLW) for one water source WS1 as Amount of leakage water in Segment $1=\mathrm{a} * \mathrm{TJ}$

Amount of leakage water in Segment $2=b *$ OHT

Amount of leakage water in Segment $3=c *$ AJ

Amount of leakage water in Segment $4=d * S T$

Amount of leakage water in Segment $5=\mathrm{e}^{*} \mathrm{IH}$

$\mathrm{TLW}=\mathrm{a}^{*} \mathrm{TJ}+\mathrm{b} * \mathrm{OHT}+\mathrm{c}^{*} \mathrm{AJ}+\mathrm{d} * \mathrm{ST}+\mathrm{e}^{*} \mathrm{IH} \rightarrow$ (Eq.1)

This can be written as a non-linear polynomial as below

$T L W=\sum_{j=1}^{a} T J_{j}+\sum_{j=1}^{b} O H T_{j}+\sum_{k=1}^{c} A J_{k}+\sum_{j=1}^{d} S T_{j}+\sum_{m=1}^{e} I H_{m}$

This non-linear polynomial is of many degrees of freedom and difficult to solve for minimum solutions. In order to find a set of feasible solutions for this model, we assume TJ, OHT and AJs are of type "fast running faucets", ST and IH are of type "dripping faucets". We calculated the leakage water in Section 3.3.

With the non-linear feasible solution, we create a linear equation for forecasting the actually delivered water as below: 


$$
\mathrm{Y}=\mathrm{A} * \mathrm{X}+(\mathrm{TLW}+\mathrm{E}) \quad \rightarrow \quad(\text { Eq. } 2)
$$

Where,

$\mathrm{Y}$ is total amount of water pumped at Water Source

$\mathrm{X}$ is the total amount of water actually delivered to end users

TLW is the total amount of water wasted through leakages.

$\mathrm{E}$ is residual, which can be ignored at the moment.

A is controlling constant also known as slope.

The above equation can be expressed as below

$$
Y_{i}=A X_{i}+\left(T L W+E_{i}\right)
$$

Where Ei is residual of data point $\mathrm{i}$. This Ei is not focused in this paper hence we reduce the equation to without Ei. Then our task became simpler, to find best fit of a line with the following characteristics

- it minimizes the sum of the squared residuals,

- the sum of the residuals is zero, and

- the point $(\operatorname{mean}(\mathrm{x})$, mean $(\mathrm{y}))$ falls on the line.

Transforming this equation for best solution, we get

$$
\min _{\forall i, T L W}\left(Y_{i} \sim X_{i}\right) \quad \rightarrow(\text { Eq.3) }
$$

\section{CALCULATE and FORECAST OF}

\section{WATERS USING PARTICULAR DATA}

World Bank has granted funds to execute water improvement projects in four municipalities in Andhra Pradesh [9].

F1: Andhra Pradesh Municipal Development Project: resettlement plan (Vol. 4): Resettlement action plan for comprehensive water supply service improvements to Guntur Municipal Corporation - packages one and three (English)

Document Type: Resettlement Plan Report No.: RP824 Document Date: JAN 01, 2014

F2: Andhra Pradesh Municipal Development Project: resettlement plan (Vol. 3): Resettlement action plan for comprehensive water supply service improvements to Manuguru Municipality (English)

Document Type: Resettlement Plan Report No.: RP824 Document Date: JUL 01, 2013

F3: Andhra Pradesh Municipal Development Project: resettlement plan (Vol. 2): Resettlement action plan for comprehensive water supply service improvements to Vizianagaram municipality (English)

Document Type: Resettlement Plan Report No.: RP824 Document Date: APR 01, 2013

F4: Andhra Pradesh Municipal Development Project: resettlement plan : Key guidelines for resettlement action planning and management (English)

Document Type: Resettlement Plan Report No.: RP824 Document Date: MAY 27, 2009

Out of these four, Vizianagaram Municipality is located in very backward area, where maintenance and management is surveyed very poor and hence prone to much water leakages and wastage of water. We will focus on this project and calculate water wastages and actual water can be delivered to create awareness on the need of proper maintenance and water leakage management processes.

\subsection{Population Analysis}

The projected population of Vizianagaram (VZM) is given in below table, (Ref. F1 document) [6][8].
Table 2: Projected Population of VZM for 30 Years

\begin{tabular}{|c|c|c|c|}
\hline VZM Pop & Town & Villages & Total \\
\hline 2011 & 200177 & 27330 & 227507 \\
\hline 2026 & 257445 & 39861 & 297306 \\
\hline 2041 & 331097 & 58137 & 389234 \\
\hline
\end{tabular}

Here, projection / forecast interval is taken 15 years, which is too large, predictions cannot be accurate or near accurate, so we need to consider for a shorter interval of 5 year. Using extrapolation method, we calculate necessary data from the below equations

$Y(x)=Y_{k-1}+\left(\frac{x-X_{k-1}}{X_{k}-X_{k-1}}\right)\left(Y_{k}-Y_{k-1}\right) \rightarrow($ Eq.4)

Where $\left(X_{k-1}, Y_{k-1}\right)$ and $\left(X_{k}, Y_{k}\right)$ are two nearest data points to the data point in focus. We calculated data using Extrapolation equation given in (Eq.3) and summarized in below table. This data is for an interval of 5 years of the total period 30 years projection given in $\mathrm{F} 2$.

Table 3: Calculated Population Data of VZM Unit

\begin{tabular}{|c|c|c|c|}
\hline Year & Town & Villages & Total \\
\hline 2011 & 200177 & 27330 & 227507 \\
\hline 2016 & 219045 & -31729 & 250774 \\
\hline 2021 & 238177 & -35863 & 274040 \\
\hline 2026 & 257445 & 39861 & 297306 \\
\hline 2031 & 282937 & 45012 & 327949 \\
\hline 2036 & 306605 & 51987 & 358592 \\
\hline 2041 & 331097 & 58137 & 389234 \\
\hline
\end{tabular}

The advantage of using data of shorter intervals is shown in the below figure. Red circles are projected by VZM and blue circles are our extrapolated data for shorter periods. Note that we get them not on red straight line but on blue Spline curve.

Projected \& Extrapolated

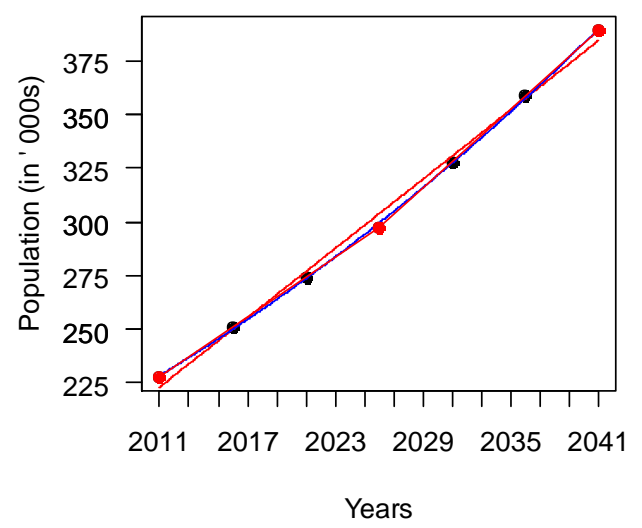

Figure 3: Projected and Extrapolated Population of VZM

\subsection{Water Requirement in VZM}

The projected water requirement of VZM as forecasted in F2 is recalculated for shorter periods and the new data is given in 
below table for 3 states of requirements Minimum, Moderate and Full requirements [7].

Table 4: Calculated Water Demand in VZM Unit for 3 States

\begin{tabular}{|c|c|c|c|}
\hline Yearly & Minimum & Moderate & Full Use \\
\hline & $7.5 \mathrm{~L} /$ day & $50 \mathrm{~L} /$ day & $135 \mathrm{~L} /$ day \\
\hline 2011 & 1706303 & 11375350 & 30713445 \\
\hline 2016 & 1880805 & 12538700 & 33854490 \\
\hline 2021 & 2055300 & 13702000 & 36995400 \\
\hline 2026 & 2229795 & 14865300 & 40136310 \\
\hline 2031 & 2459618 & 16397450 & 44273115 \\
\hline 2036 & 2689440 & 17929600 & 48409920 \\
\hline 2041 & 2919255 & 19461700 & 52546590 \\
\hline
\end{tabular}

Water Demand Forecast

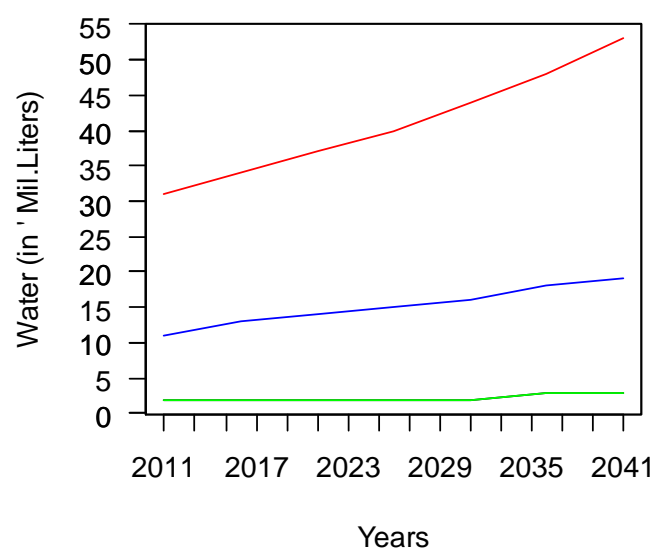

Figure 4: Water Requirement Forecast for 3-States

Green color is for $7.5 \mathrm{~L} / \mathrm{day}$, Blue is for $50 \mathrm{~L} /$ day and Red is for $135 \mathrm{~L} /$ day estimates for an year.

\subsection{Water Leakage Calculations}

Now we will calculate the water leakages for the described water leakage patterns in Section 2. For the given water requirements and we calculate water leakage for the leakage patterns described in Section 2.1. We categorize the pipes into two types for calculating leakage amounts purpose. Pipes, Method, Time / Volume in the said segments are considered as given in the below table.

Table 5: Fast Running and Dripping Faucets in Patterns

\begin{tabular}{|c|c|c|c|}
\hline Segment & Type & Method & Time/Volume \\
\hline Segment 1 & Type 1 & \multirow{3}{*}{$\begin{array}{c}\text { Fast } \\
\text { Running }\end{array}$} & $10 \mathrm{sec}$ \\
\hline Segment 2 & Type 1 & & $20 \mathrm{sec}$ \\
\hline Segment 3 & Type 1 & & $30 \mathrm{sec}$ \\
\hline Segment 4 & Type 2 & \multirow{2}{*}{ Dripping } & 3 drops \\
\hline Segment 5 & Type 2 & & 5 drops \\
\hline
\end{tabular}

Type 1: Fast Running Faucets

For larger/more rapid leaks - hold an 8 ounce cup under the dripping fixture and time, in seconds, how long it takes to fill the cup ( $8 \mathrm{oz}=0.2369$ liters).
Type 2: Dripping Faucets

For smaller/slower leaks - count the number of drips in one minute from the leaky fixture. Note: 5 drips per second amounts to a steady stream.

With the formula: rate $\mathrm{Z}=(3 / 5) \mathrm{M}$ means that in 5 minutes 3 ounce of water is wasted through leakages. We now calculate how much water is expected to go out through leakages for days, months and years as shown in the below table.

Table 6: Liters for given time per period

\begin{tabular}{|l|l|r|r|r|}
\hline & Per / Ltr & \multicolumn{1}{l|}{ Day } & \multicolumn{1}{l|}{ Month } & \multicolumn{1}{l|}{ Year } \\
\hline Sg1 & 8oz/10 Sec & 2044 & 61323 & 746103 \\
\hline Sg2 & 8oz/20 Sec & 1022 & 30661 & 373051 \\
\hline Sg3 & $8 \mathrm{oz} / 30 \mathrm{Sec}$ & 681 & 20441.1 & 248700 \\
\hline $\mathrm{Sg} 4$ & $3 \mathrm{drop} / \mathrm{min}$ & 1.64 & 49.2 & 598.6 \\
\hline Sg5 & $5 \mathrm{drops} / \mathrm{min}$ & 2.73 & 81.9 & 996.45 \\
\hline Total & & 3751.37 & 112556.2 & 1369449.1 \\
\hline
\end{tabular}

This is just one set of solutions for the Eq.1 formulated in Section 2.2. We go ahead with whatever data we have in our hand. Now we have the water leakage information for one water source.

Similarly, we can calculate water leakage information for other water sources for the described piping patterns given in Section 2.1. However, we do not consider the solutions for all Water Sources now. To do this we need to extend the research to more complicated mathematical formulations or more assumptions.

\subsection{Forecast Actual Water Delivery}

Now we have data for water demand and data for leakage water on hand. We can now forecast actual water that will be delivered to the end users, after expected leakages for the given 3-states, Minimum, Moderate and Full requirement. The calculated data is given in the below table.

Table 7: Actual Delivered Water to The End Users

\begin{tabular}{|c|c|c|r|}
\hline \multicolumn{1}{|c|}{ Year } & \multicolumn{1}{c|}{ Minimum } & \multicolumn{1}{c|}{ Moderate } & \multicolumn{1}{c|}{ Full } \\
\hline \multicolumn{1}{l|}{ for } & 7.5L/day & \multicolumn{1}{c|}{ 50L/day } & 135L/day \\
\hline 2011 & 336854 & 10005901 & 29343996 \\
\hline 2016 & 511356 & 11169251 & 32485041 \\
\hline 2021 & 685851 & 12332551 & 35625951 \\
\hline 2026 & 860346 & 13495851 & 38766861 \\
\hline 2031 & 1090169 & 15028001 & 42903666 \\
\hline 2036 & 1319991 & 16560151 & 47040471 \\
\hline 2041 & 1549806 & 18092251 & 51177141 \\
\hline
\end{tabular}




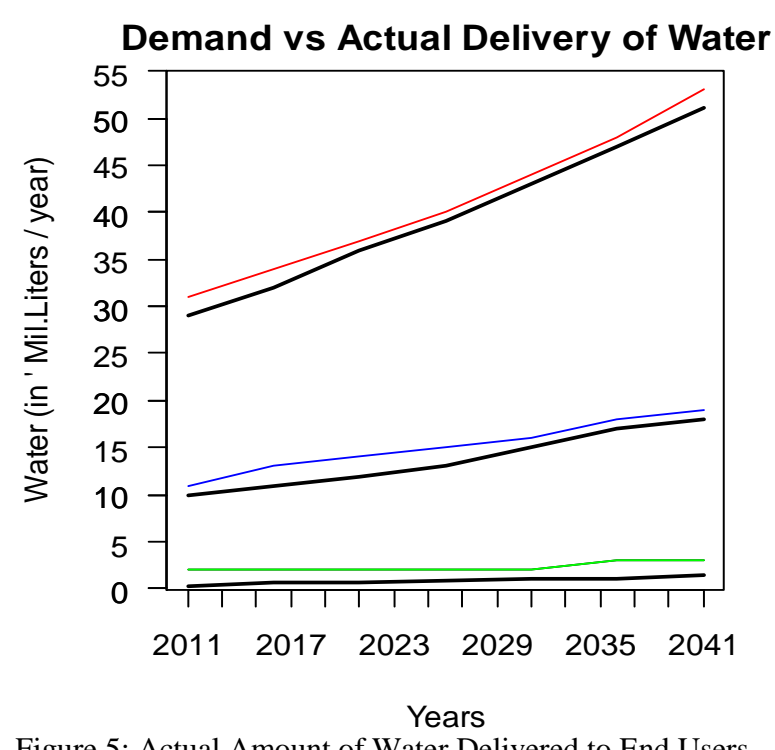

Figure 5: Actual Amount of Water Delivered to End Users

Demanded water curves are shown as Green: $7.5 \mathrm{~L}$, Blue: 50L, Red: 135L. The thick black curves show the actual water delivery.

The usual regression least squares method and mathematical calculations are used to find the controlling parameter values for "A" in Eq. 2. Further analyzed for crucial values and are summarized in the below table.

Table 8: Analysis Results

\begin{tabular}{|l|l|l|l|l|}
\hline & State & $\mathbf{7 . 5} \mathbf{~ L}$ & $\mathbf{5 0} \mathbf{~}$ & $\mathbf{1 3 5} \mathbf{~}$ \\
\hline \multirow{2}{*}{$\begin{array}{l}\text { Correlati } \\
\text { on }\end{array}$} & Demand & 0.791 & 0.994 & 0.995 \\
\cline { 2 - 5 } Intercept & Delivery & 0.959 & 0.990 & 0.999 \\
\hline & Demand & -70.071 & -505.828 & $-1.421 \mathrm{e}+03$ \\
\hline & Delivery & -67.159 & -550.671 & $-1.451 \mathrm{e}+03$ \\
\hline p-value & Demand & 0.034 & $5.601 \mathrm{e}-06$ & $3.404 \mathrm{e}-06$ \\
\hline & Delivery & 0.00063 & $1.928 \mathrm{e}-05$ & $7.396 \mathrm{e}-08$ \\
\hline
\end{tabular}

\subsection{Summary of Analysis Results for VZM}

From Table 8, one can observe the correlation values for demand and actual delivery is near 1. A correlation of 1.00, whether it's positive or negative, is a perfect correlation. It means that as volumes on one of the two variables increase or decrease, the volumes on the other variable increase or decrease by the same magnitude.

If $\mathrm{X}$ in Eq.2 (total water of actually delivery) never $=0$, then the intercept has no intrinsic meaning. But if all water pumped at Water Source is leaked out in any segments of type 1, we get no water to actual delivery, here $\mathrm{X}$ becomes 0 . So intercept is calculated for this model. From these values we can observe more difference in intercept for Demand and Delivery for case 50L. Other cases do not show much greater difference.

A small p-value (typically $\leq 0.05$ ) indicates strong evidence against the null hypothesis, so you reject the null hypothesis. A large p-value $(>0.05)$ indicates weak evidence against the null hypothesis, so you fail to reject the null hypothesis. pvalues very close to the cutoff $(0.05)$ are considered to be marginal (could go either way). So, we report the p-value for readers can draw their own conclusions. p-values in Table 8 for all the three cases, show strong evidence against the nullhypothesis.
It means that there is a strong relationship between Demand and Delivery through Leakage Water volumes.

\subsection{Extension to Other 3 Projects}

We need to design the piping patterns in the distribution system and calculate the leakage water volumes and forecast the volumes of water actual delivery to end users for the remaining three projects: F1 - Guntur Municipal Corporation, F2 - Munuguru Municipality and F4 - resettlement plan, to effectively utilize the water available at Water Sources.

\section{DISCUSSIONS}

Availability and Demand are key issues to the administrators and decision makers. Wastage and Delivery are importance to us hence induced into the system as shown in the below depiction.

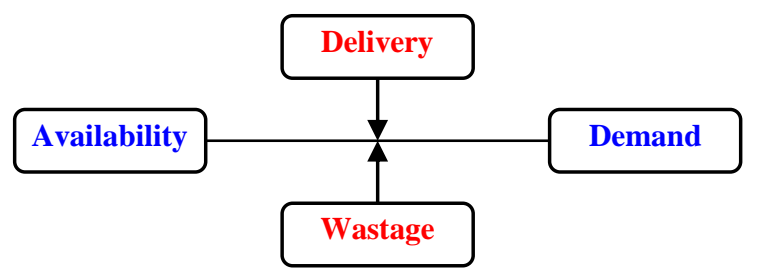

Water distribution systems are not necessarily same in all cases, but an essential pattern is same everywhere. Leakage Water is not a straightforward calculation, involves many unknown variable, hence becomes a non-linear in nature.

But linearization of such non-linear systems provided insight and calculation feasibility. Forecasting and analyzing the calculated results are comparable to any other similar systems published so far, however, the superiority of our methods came from the consideration of ignored variables Leakage Water and Actual Delivery together in one system.

\section{CONCLUSIONS}

Most projects funded by global organizations, consider the need or demand and proposed solutions as primary concepts and the intrinsic maintenance plans and strategies left secondary, or in most cases are neglected / ignored. The projects that forecast water demand for coming years also fall into the same category and less measured. As described in the previous sections, administrators just see the Demand and Availability, but researchers see differently, In this research, we identified that Wastage and Delivery play a great role in the supply cycle. We studied the problem in researcher view and modeled the scenario, forecast and analysis of Wastage and Delivery issues are presented.

First of all, What if we have less (population and water requirement) data available? To address this, we need to use extrapolation methods to create required data. To study the problem, we have very less data of population projections available from the project proposals. Using extrapolation methods, we created more necessary data for shorter intervals. Then, what if we have missing parameters? We identified the missing parameters, Wastage as Leakage Water, Delivery as Actual Delivery to consumers.

And then, what if we don't have a model of infrastructure information? To workout with such scenarios, we created a model of piping patterns and a model of water traverse. If you have enough data, just calculations can give some results, 
however, ideas, methodology and mathematical formulation provide scientific results. This is what we did in sections 2 and 3. After all, if you don't analyze the results administrators or decision makers don't understand the perfection of the model presented. We did this analysis in Analysis section.

The ideas and methodologies presented in this research paper can be used with scenario matching modifications to identify and avoid most of the leakage problems and can deliver more water to the consumers. The application of the results can be extended to municipalities or distribution agencies, who distribute the clean water to the consumers.

Finally, we conclude the paper with some avenues for further extension. There is lot of scope for research using the proposed methodologies. To specify some directions, we can extend (1) to handle multiple Water Sources, (2) to compute data for the complexity (nonlinearity) of number of leakage points and a variety of faucets with uniform \& non-uniform leakage volumes, (3) to introduce environmental parameters, etc. Further study on these issues gives more accurate results, but we need to pay time and money.

\section{ACKNOWLEDGEMENTS}

This research was funded by RAMTEJ Technologies Corp., Japan under Grant No. CECT-P3-042015. We acknowledge our deepest gratitude for this support.

\section{REFERENCES}

[1] Growing Blue, "Leaks in Water Distribution Systems", http://growingblue.com/case-studies/leakages-in-waterdistribution-systems/ Jul 2012.

[2] Marcus Bess H, Rakowski William, et. al "Assessing motivational readiness and decision making for exercise", Health Psychology, Vol 11(4), 1992, 257-261

[3] Michael Marmot, Sharon Friel, Ruth Bell et. al. "Closing the gap in a generation: health equity through action on the social determinants of health", Volume 372, No. 9650, Nov 2008, p1661-1669

[4] Sherri Hartzell, "Types of Planning: Strategic, Tactical, Operational \& Contingency Planning", http://study.com/academy/lesson/

[5] W. Feller, An Introduction to Probability Theory and Its Applications, 2nd edition, Vol. II, John Wiley \& Sons, New York, 1971.

[6] Turban, E., Aronson, J.E., and Liang, T.P., "Decision Support System and Intelligent System", 7th Edition, Pearson Education Inc., Upper Saddle River, New Jersey, 2005.

[7] World Health Organization Technical Report TN09, 2011. Water Sanitation Health http://www.who.int/water_sanitation_health/emergencies /qa/emergencies_qa5/en/

[8] Vizianagaram Municipality, "Resettlement Action Plan for Comprehensive Water Supply Service Improvements To Vizianagaram Municipality" PR824 V2, Vizianagaram Municipality, April 2013.

[9] Brian Reed, Bob Reed, World Health Organization, "Technical Notes on Drinking-Water, Sanitation and Hygiene in Emergencies", WEDC, No.9, 2000. 